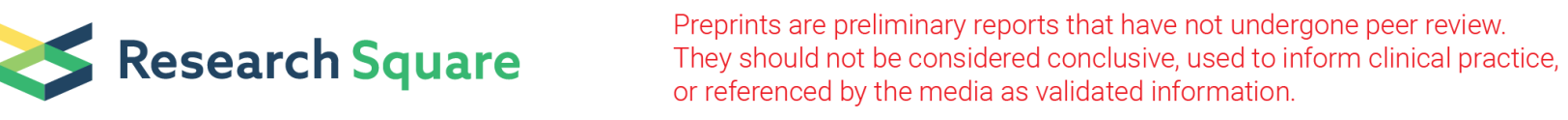

\title{
Exploring Patient Perceptions of Repetitive Transcranial Magnetic Stimulation as a Treatment for Chronic Musculoskeletal Pain: A Qualitative Study
}

\author{
G Stillianesis \\ Western Sydney University \\ R Cavaleri \\ Western Sydney University \\ SJ Summers \\ Western Sydney University \\ cY Tang ( $\square$ clarice.tang@westernsydney.edu.au ) \\ Western Sydney University
}

\section{Research Article}

Keywords: non-invasive brain stimulation, rTMS, chronic musculoskeletal pain, chronic pain management, perceptions

Posted Date: June 30th, 2021

DOI: https://doi.org/10.21203/rs.3.rs-646776/v1

License: (c) This work is licensed under a Creative Commons Attribution 4.0 International License. Read Full License 


\section{Abstract}

Background: Repetitive transcranial magnetic stimulation (rTMS), a form of non-invasive brain stimulation, represents a novel avenue for the management of chronic musculoskeletal pain. Despite evidence for the effectiveness of rTMS in chronic pain conditions, the clinical uptake of rTMS remains limited. One plausible reason for this discrepancy may be a lack of understanding regarding patient perceptions and their willingness to engage with rTMS. Therefore, this study aimed to explore patient perceptions of rTMS as a treatment for chronic musculoskeletal pain.

Methods: Using a phenomenological approach, this qualitative study utilised a semi-structured interview to explore overall knowledge, pre-conceived concerns and attitudes regarding rTMS as a treatment for chronic musculoskeletal pain. All participants had a diagnosis of chronic musculoskeletal pain, a history of seeking treatment, and no prior experience with rTMS. The interviews were transcribed verbatim and analysed thematically.

Results: Majority of the participants were willing to consider the use of rTMS as a treatment option, with most having high expectations regarding the effectiveness of the treatment due to its sophisticated appearance. Acceptance to utilise rTMS was influenced by knowledge of pain, cost and travel, and the perceived sophistication of the intervention.

Conclusions: This is the first qualitative study to the authors' knowledge that explores the perception of rTMS as a treatment among people with chronic musculoskeletal pain, a key gap in the current literature. Repetitive transcranial magnetic stimulation appears to be accepted as a treatment option amongst individuals with chronic musculoskeletal pain. Adequate levels of funding support, accessibility and the need for medical professions to endorse the treatment are important considerations that influenced uptake. Developing targeted strategies to address these considerations may encourage use of rTMS in a clinical chronic pain setting.

\section{Background}

Chronic pain affects approximately 1.5 billion people worldwide and represents a substantial socioeconomic burden [1]. In addition to health care expenditure exceeding $\$ 630$ billion worldwide, chronic musculoskeletal conditions are associated with reduced quality of life and elevated rates of co-morbid psychological issues [2]. Despite increasing research over the last twenty years, current management approaches for chronic musculoskeletal conditions, such as lower back pain and osteoarthritis, demonstrate small-to-moderate effects at best [3]. This has led to the exploration of novel avenues, such as repetitive transcranial magnetic stimulation (rTMS).

Accumulating evidence suggests that repetitive transcranial magnetic stimulation (rTMS) is a safe and effective treatment for chronic musculoskeletal pain [4]. This form of non-invasive brain stimulation involves the delivery of time-varying magnetic pulses that pass through the skull and induce secondary electrical currents in the underlying cortical tissue [4]. The use of rTMS has been shown to produce comparable or greater analgesic effects in complex regional pain syndrome, neuropathic pain, and fibromyalgia than those observed with non-pharmacological interventions such as exercise $[5,6]$. Despite the presence of growing literature to support the effectiveness of rTMS, the use of rTMS has yet to be translated into clinical practice.

With reference to the Translational Research Continuum Model [7, 8], many of the current rTMS studies fall under the 'T2 translational phase' whereby the focus of these studies is to establish the safety and efficacy of the treatment. The next phase of research focuses on the 'implementation and adoption' of the technique within clinical practice. Assessing the acceptability and feasibility of implementing rTMS in clinical practice for people with chronic musculoskeletal pain is an important element to such research, which is currently absent in the literature [9]. Exploring the perceptions of rTMS among naïve populations with chronic musculoskeletal pain will provide not only preliminary indications regarding the acceptability and feasibility of rTMS, but also identify potential barriers hindering the implementation of rTMS in clinical practice. 
Accordingly, the aim of this study was to explore patient perceptions regarding the use of rTMS as a treatment for chronic musculoskeletal pain. This study will provide rich insight into potential barriers and facilitators influencing the uptake of rTMS for pain management in the clinical setting.

\section{Methods}

This study has been reported in accordance with the Consolidated criteria for reporting qualitative research (COREQ) checklist [10].

\section{Study design and participants}

Through the use of semi-structured interviews, this qualitative study utilised a phenomenological approach to explore the perceptions of rTMS among people with chronic musculoskeletal pain. These individuals had no previous experience with rTMS. The phenomenological approach was used to allow exploration of real-life experiences and the meanings people attribute to them. This approach provides rich insight into patient perceptions regarding therapeutic interventions [11].

A purposive sampling strategy was used to recruit people with chronic musculoskeletal pain. People were eligible for inclusion if they reported musculoskeletal pain that was present for longer than three months [12], were currently undergoing treatment from a health professional, and had not previously experienced rTMS. By including people who have never had experience with rTMS, we aimed to capture perceptions of the intervention from a naïve perspective. In addition, by targeting only people who were actively accessing pain management services, we were targeting the population that would most likely be referred to rTMS in a clinical setting [13]. People who had a known history of cognitive deficits and who required assistance with English were excluded from this study.

Participants were recruited via social media channels (e.g., Facebook, Twitter) and snowball sampling [11, 14]. Upon expressing interest in participating in the study, potential participants were screened for eligibility over the phone by a member of the research team (GS). If eligible, GS followed up with the respective individuals to obtain written informed consent at time of recruitment. This study received ethical approval from the local institutional Ethics Committee (H13647).

\section{Setting and Data Collection}

Following receipt of informed consent, GS arranged a convenient time with the participants to conduct the interview. Participants were given the option of either completing the interview face-to-face or via phone. Prior to the interview, participants provided data regarding their age, gender, level of education, employment status, and chronic pain condition (Additional File 1). The Depression, Anxiety and Stress Scale (DASS-21) was also included to provide insight into the participant affect and level of physiological arousal[15]. Additionally, participants were asked to provide an indication of the duration of their chronic pain condition and rated their perceived level of pain using an 11-point numerical rating scale (NRS). Participants were asked to select a single number on a scale between 0 and 10 , which best represented the intensity of their pain. Zero represented 'no pain at all', whereas 10 represented 'the worst pain ever possible'. The NRS was chosen due to its feasibility, relative simplicity and ease of administration [16]. The above baseline information enabled us to provide a comprehensive description of the participants' background.

\section{Development of semi-structured interview questions}

Semi-structured interview questions were used to promote flexibility and adaptability to participant responses [11]. Using the theoretical domain framework as a reference [17], the interview included questions pertaining to patient knowledge, expectations, fear/concerns and attitudes towards rTMS (Additional File 2). The theoretical domain framework was chosen in this instance as it is a well-established framework used to explore the determinants of behaviour and has been widely used in literature to explore implementation problems associated with evidence-based interventions [18]. The framework 
has also been used previously to investigate the uptake of evidence-based interventions [17]. This approach is consistent with previous studies investigating perceptions of rTMS among people with psychological conditions [19]. The wording of questions was further developed and refined via consultation of content experts and researchers experienced with the therapeutic use of rTMS [19]. As the study only included people who have never engaged in rTMS previously, a standardised introduction to the purpose of rTMS was included (Additional File 2). This provided participants with context that facilitated the completion of the interview.

Pilot interviews were conducted prior to data collection to refine interview questions in response to unforeseen barriers. Predominantly open-ended questions were utilised to invite participants to give detailed responses [11]. Probing questions were also utilised to clarify information and prompt participants to further explore their thoughts [11]. The semi-structured interview required approximately 20 minutes to complete.

The interview was audio-taped and field notes were taken to facilitate data analysis. The audio recordings were transcribed verbatim using NVIVO (QRS international v12) transcription services. The transcripts were then sent to each participant for member checking to confirm the accuracy of the transcribed data [20].

\section{Data Analysis}

An inductive thematic analysis was used to analyse the transcripts according to the six phases described by Braun and Clarke [21]. All members of the research team read the transcripts in their entirety independently to elicit meaning and patterns for the study $[11,21]$. Then, two of the researchers (GS and CT) independently coded the transcripts line-by-line, using an electronic software program, Quirkos v 2.3.1 (Quirkos Software, 2013). A code book was created and revised for consistency of application between the researchers across the transcripts. Upon completion of the coding process, the entire research team met to discuss the codes in the code book and analysed the connections between the codes so as to identify the emerging key themes and sub-themes of the study [11]. These themes were then illustrated with a description and supported with quotes from the transcripts to ensure that they were adequately represented and grounded in the data [11]. Recruitment for this study continued until the point of data saturation when no new themes were added during the last three interviews [21].

Several strategies were used to enhance the trustworthiness of this study by ensuring credibility, criticality and transferability [22]. CT is an experienced researcher in qualitative methods and provided appropriate feedback for refinement of the analysis process carried out by GS. The use of a code book also increased the dependability between researchers. Considering the varying expertise and experience of the research team, completing the analysis as a group enabled the process to be as transparent as possible [23]. GS was a current physiotherapy student who had no prior experience in the area of rTMS and possessed no vested interest in supporting or rejecting the clinical utility of the technique. GS performed the semi-structured interviews under training by $\mathrm{CT}$, who is an experienced qualitative researcher. $\mathrm{RC}$ and SS are experienced researchers in the field of rTMS and also have experience in data analysis and coding of transcripts for qualitative studies. None of the researchers in this project had a dependent therapist-patient relationship with the participants.

\section{Results}

\section{Characteristics of participants}

A total of 15 participants were recruited for this study and all participants engaged in face-to-face interviews. Participant characteristics are summarised in Table 1. Of the 15 participants, 10 were female (66.7\%) and five were male (33.3\%). The mean age of the participants was $38 \pm 15$ years (Table 1$)$. The majority of participants were employed $(60 \%$, $n=9)$, with some participants identifying as students $(20 \%, n=3)$, self-employed workers $(13.3 \%, n=2)$, or retired $(6.7 \%, n=1)$. Almost half 
of the participants had a year 12 or equivalent education $(46.7 \%, n=7)$, with five $(33 \%)$ receiving a Bachelor's Degree and three (20\%) possessing a Diploma.

\begin{tabular}{|c|c|c|c|c|c|c|c|c|c|c|}
\hline \multirow[t]{2}{*}{$\mathbf{N}$} & \multirow[t]{2}{*}{ Sex } & \multirow[t]{2}{*}{ Age } & \multirow{2}{*}{$\begin{array}{l}\text { Employment } \\
\text { status }\end{array}$} & \multirow{2}{*}{$\begin{array}{l}\text { Level of } \\
\text { education }\end{array}$} & \multirow{2}{*}{$\begin{array}{l}\text { CMP } \\
\text { diagnosis }\end{array}$} & \multirow{2}{*}{$\begin{array}{l}\text { Pain } \\
\text { (out } \\
\text { of } \\
10)\end{array}$} & \multirow[b]{2}{*}{$\begin{array}{l}\text { Duration } \\
\text { of pain }\end{array}$} & \multicolumn{3}{|c|}{ DASS-21 Scores } \\
\hline & & & & & & & & Depression & Anxiety & Stress \\
\hline 1 & $F$ & 61 & Retired & $\begin{array}{l}\text { Bachelor } \\
\text { Degree }\end{array}$ & Hip bursitis & 2 & $\begin{array}{l}5-10 \\
\text { years }\end{array}$ & 6 & 2 & 24 \\
\hline 2 & $\mathrm{~F}$ & 20 & Student & $\begin{array}{l}\text { Year } 12 \\
\text { or equiv. }\end{array}$ & $\begin{array}{l}\text { Osgood- } \\
\text { schlatters }\end{array}$ & 7 & $3-4$ years & 2 & 8 & 4 \\
\hline 3 & $\mathrm{~F}$ & 23 & Employed & $\begin{array}{l}\text { Bachelor } \\
\text { Degree }\end{array}$ & $\begin{array}{l}\text { Peroneal } \\
\text { tendonitis }\end{array}$ & 6 & $\begin{array}{l}5-10 \\
\text { years }\end{array}$ & 4 & 4 & 14 \\
\hline 4 & $\mathrm{~F}$ & 51 & Employed & $\begin{array}{l}\text { Year } 12 \\
\text { or equiv. }\end{array}$ & $\begin{array}{l}\text { Chronic neck } \\
\text { pain* }\end{array}$ & 7 & $3-4$ years & 6 & 4 & 22 \\
\hline 5 & $\mathrm{~F}$ & 21 & Employed & $\begin{array}{l}\text { Year } 12 \\
\text { or equiv. }\end{array}$ & $\begin{array}{l}\text { Previous NOF } \\
\#\end{array}$ & 7 & $\begin{array}{l}5-10 \\
\text { years }\end{array}$ & 0 & 0 & 2 \\
\hline 6 & $F$ & 26 & Employed & $\begin{array}{l}\text { Bachelor } \\
\text { Degree }\end{array}$ & $\begin{array}{l}\text { Chronic neck } \\
\text { pain* }\end{array}$ & 6 & $\begin{array}{l}15+ \\
\text { years }\end{array}$ & 0 & 10 & 18 \\
\hline 7 & $\mathrm{~F}$ & 50 & Employed & $\begin{array}{l}\text { Year } 12 \\
\text { or equiv. }\end{array}$ & Golfers elbow & 6 & $\begin{array}{l}3-6 \\
\text { months }\end{array}$ & 2 & 0 & 4 \\
\hline 8 & $M$ & 21 & Student & $\begin{array}{l}\text { Year } 12 \\
\text { or equiv. }\end{array}$ & $\begin{array}{l}\text { De Quervain's } \\
\text { Tenosynovitis }\end{array}$ & 5 & $\begin{array}{l}3-6 \\
\text { months }\end{array}$ & 6 & 4 & 2 \\
\hline 9 & M & 50 & $\begin{array}{l}\text { Self- } \\
\text { employed }\end{array}$ & Diploma & $\begin{array}{l}\text { Plantar } \\
\text { fasciitis }\end{array}$ & 8 & $\begin{array}{l}5-10 \\
\text { years }\end{array}$ & 2 & 0 & 8 \\
\hline 10 & $\mathrm{~F}$ & 51 & Employed & $\begin{array}{l}\text { Bachelor } \\
\text { Degree }\end{array}$ & $\begin{array}{l}\text { Chronic } \\
\text { NSLBP }\end{array}$ & 6 & $\begin{array}{l}1-2 \\
\text { years }\end{array}$ & 8 & 2 & 18 \\
\hline 11 & $F$ & 51 & $\begin{array}{l}\text { Self- } \\
\text { employed }\end{array}$ & Diploma & $\begin{array}{l}\text { Knee } \\
\text { osteoarthritis }\end{array}$ & 5 & $\begin{array}{l}3- \\
\text { 6months }\end{array}$ & 20 & 20 & 28 \\
\hline 12 & $M$ & 18 & Student & $\begin{array}{l}\text { Year } 12 \\
\text { or equiv. }\end{array}$ & $\begin{array}{l}\text { Chronic } \\
\text { NSLBP }\end{array}$ & 9 & $2-3$ years & 0 & 10 & 8 \\
\hline 13 & $M$ & 51 & Employed & Diploma & $\begin{array}{l}\text { Chronic } \\
\text { NSLBP }\end{array}$ & 7 & $2-3$ years & 2 & 0 & 14 \\
\hline 14 & $M$ & 34 & Employed & $\begin{array}{l}\text { Year } 12 \\
\text { or equiv. }\end{array}$ & $\begin{array}{l}\text { Patella- } \\
\text { femoral knee } \\
\text { pain }\end{array}$ & 5 & $\begin{array}{l}3-6 \\
\text { months }\end{array}$ & 0 & 2 & 4 \\
\hline 15 & $\mathrm{~F}$ & 47 & Employed & $\begin{array}{l}\text { Bachelor } \\
\text { Degree }\end{array}$ & $\begin{array}{l}\text { Chronic neck } \\
\text { pain* }\end{array}$ & 9 & $\begin{array}{l}5-10 \\
\text { years }\end{array}$ & 4 & 8 & 24 \\
\hline \multicolumn{11}{|c|}{$\begin{array}{l}\mathrm{N}=\text { number; } \mathrm{F}=\text { female; } \mathrm{M}=\text { male; } \mathrm{CMP}=\text { Chronic musculoskeletal pain; * = no formal diagnosis received; Equiv. = } \\
\text { equivalent; NOF \# = neck of femur fracture; NSLBP = non-specific low-back pain; } \mathrm{SD}=\text { Standard deviation; Depression } \\
\text { subscale: Normal }(0-9) \text {, mild }(10-13) \text {, moderate }(14-20) \text {, severe }(21-27) \text { \& extremely severe }(+28) \text {; Anxiety subscale: } \\
\text { Normal }(0-7) \text {, mild }(8-9) \text {, moderate }(10-14) \text {, severe }(15-19) \text { \& extremely severe }(+20) ; \text { Stress subscale: Normal }(0-14) \text {, mild } \\
(15-18) \text {, moderate (19-25), severe }(26-33) \text { \& extremely severe }(+34)\end{array}$} \\
\hline
\end{tabular}

Most participants $(80 \%, \mathrm{n}=12)$ reported receiving a formal chronic musculoskeletal pain diagnosis from a healthprofessional, but three participants (20\%) had undiagnosed chronic pain. Overall, ten participants (66.7\%) reported living with their pain for greater than two years, with one participant (6.7\%) reporting living with their pain for over 15 years. In 
addition, average pain levels at the time of the interview were 6.3 out of 10, with scores ranging from 2 to 9 (Table 1). Average depression, anxiety and stress scores (DASS-21) were relatively similar across participants (Table 1). The majority of participants reported seeking health care services from general practitioners $(66.7 \%, n=10)$, physiotherapists $(60 \%, n=9)$ and chiropractors $(60 \%, n=9)$ to manage their condition.

\section{Study themes}

From analysis of the fifteen semi-structured interviews, the key themes that influenced an individual's acceptance of rTMS for chronic pain management were i) the individual's perceptions regarding the sophisticated nature of rTMS, ii) the accessibility and availability of rTMS, and iii) the individual's knowledge regarding pain and rTMS. Illustrative quotes were selected from the transcripts to support these themes. A table that illustrates how codes contributed to sub-themes and main themes is provided in Additional File 2.

Theme 1: "It looks like it is going to have a big impact"- equipment appearance influenced the likelihood of using rTMS.

Initial impressions of rTMS were consistent across participants, with comments relating to the sophisticated appearance of the intervention and the perceived technological advancements in pain management. Participants often expressed that the complex appearance of rTMS created greater expectations regarding pain relief than conventional therapies.

“It looks like it's going to make a big enough impact. I don't think that people would spend time and money to develop this new product to only slightly make your pain better. I can take a Panadol and do the same thing. So, it is new and improved, it's better than what we've got so far, it should make a lot of difference." (P3)

"It looks more elaborate, like more than a physiotherapist talking to me and saying here is an elastic band and your exercises. It is high-tech and it looks like it reflects the growing advancements in pain relief, so I would expect better pain relief." (P8)

Although participants expected rTMS to possess greater pain relieving attributes than other therapies, many indicated a degree of fear or uncertainty regarding the treatment. The only recognisable feature, by all participants, was the "dentist chair". The lack of familiarity with rTMS often created apprehension.

“It looks a bit confronting because there are so many things, and you don't know what they are." (P1)

"When you said copper stimulating the brain, that sort of sent a bit of warning - what does that mean? Is it radiation or harmful in any way?" (P10)

Concerns were also raised regarding the advanced nature of rTMS and the belief that a trained health professional would need to administer the intervention. Participants most commonly acknowledged physicians as a trusted source of guidance for considering rTMS. The majority of participants also stated they would utilise rTMS if advocated by friends who had a positive experience of the treatment. Additionally, participants dismissed the notion of home-based rTMS, indicating that it would be unsafe or of a lower quality.

"I don't know ... just in-case I hit the wrong part of my brain, or put it [rTMS device] on the wrong thing. I would feel more comfortable if a professional, who had been trained in this device, was using it." (P2)

"Even if you think about at-home teeth whitening or like laser hair removal and you compare that to when you go to see a professional. The at-home ones are always less strong and less effective. So, I feel like perhaps if there is a professional administering it, then it must be at a higher level and more effective." (P6)

"If my doctor recommended it I would definitely do it. I trust her and she is pretty honest and would tell me if it was a waste or not." (P15) 
The familiarity and willingness to utilise technology also impacted on the individual's willingness to engage with rTMS. Participants identified that younger people may be more likely to utilise rTMS when compared to older generations, due to a perceived increased familiarity with technology.

"Upbringing around technology, they [younger generation] have been around it more. Technology is changing. Whereas, maybe an older generation would think about it a bit more." (P14)

"I think it's harder for an older person to try new technology, especially if they don't understand it." (P15)

Potential generational differences were also highlighted across participant responses, with older interviewees typically demonstrating greater reluctance to consider utilisation of rTMS. For example, a 51-year-old participant (P7) reported that they would have "a 50/50 commitment about doing it", while a 21-year-old participant (P8) emphasised that they "would be happy to give it a red hot go." This is supported by participant perspectives of the safety of rTMS. Younger participants believed rTMS had to be a safe intervention to be used clinically and may result in only minor side-effects. For example, a 23-year-old participant suggested that rTMS "could affect sleep or moods" (P3). In contrast, older participants were more sceptical of rTMS as they perceived the intervention to be associated with more complications. This is reflected in a 51-yearold participant that suggested engagement in rTMS could cause the "development of cancer because it is transmitting something" (P10).

In terms of pain experience, participants identified that more severe or debilitating pain would warrant greater consideration of rTMS as a treatment avenue. In comparison, a small number of participants were satisfied with their current pain management and so were less inclined to consider rTMS.

"If I had the pain, chronic pain that was debilitating, that was really impacting on my day-to-day, and I do have a friend that is in this position, where they just cannot function ... then I would probably look at this [rTMS] as an option" (P1)

"I am happy living with my pain. I reckon I could cope with it. There are other natural ways I can try and manage my pain." (P14)

\section{Theme 2: Concerns over cost and access impact willingness to utilise rTMS}

Cost and access were two of the main factors that influenced participant willingness to use rTMS. Personal factors that were reported to influence perceptions regarding rTMS included travel time and expenses associated with the treatment. Participants indicated that their willingness to engage with rTMS would likely depend upon its convenience and cost when compared to their current management strategies. Participants suggested their willingness to pay between $\$ 20$ to $\$ 300$ for the treatment, with some participants inquiring about government rebate incentives. Participants also communicated that extended travel times surpassing one hour or repeated sessions would represent a significant barrier, often expressing a preference for a longer session that occurred on one day rather than multiple sessions over consecutive days. These perceptions were shared among participants regardless of age. There was a consistent belief that participants would be willing to spend more or travel further if pain relief was guaranteed, but the extent of pain relief required varied between participants.

"Cost. If it is not too expensive and in terms of length - if it is a whole hour you have to spend on the machine then I probably wouldn't but if it's like a quick 15-30min thing and the research shows that it has quite good benefit then I would be happy to do that." (P8)

"I have had it [chronic musculoskeletal pain] for so long I would be willing to pay more if I knew it was a guaranteed thing. If you have no idea, you would want to try it but hope it doesn't cost that much." (P4)

"It is quite a big commitment. I mean you have to travel there ... assuming whoever is running this procedure is not late ... things like that. So, it would take a good one to two hours out of your day ... it is quite a lot I think." (P2) 
Overall, a lack of knowledge and understanding of the intervention was perceived to be the biggest barrier to utilising rTMS. Participants often indicated that their decisions would be informed by the physiological justification of the treatment, documentation, and research regarding its effectiveness and potential side-effects. One participant suggested that a factsheet with information of rTMS would be helpful in the decision-making processes.

"I'd like to know exactly what is does, what the benefits of it are and what areas it treats. All that sort of stuff, like a fact sheet of what it [rTMS] is." (P10)

Furthermore, the lack of knowledge in pain science affected the likelihood of participants accepting rTMS, especially if they had pain in the extremities as compared to central head and neck pain. This was evident by the fact that participants identified mental health conditions, headaches, and brain tumours as the primary indicators for the use of rTMS. Further, participants admitted being less willing to utilise rTMS if their pain was localised peripherally, perceiving the treatment to be less effective.

"I have ankle pain ... I think it would be weird to treat my brain, or ineffective to treat. Like it just doesn't seem like it would actually treat the affected area of pain because it's not specifically targeting that area." (P3)

"I couldn't see how it would work in bone issues ... it is a bit interesting to me" (P2)

\section{Discussion}

This study is the first to qualitatively investigate patient perceptions of rTMS as a treatment for chronic musculoskeletal pain. Acceptance to utilise rTMS as a treatment option was influenced by knowledge of pain, cost and travel, and the perceived sophistication of the intervention. Participants were also more willing to consider rTMS when recommended by a trusted medical professional. Moreover, participants were generally accepting of rTMS as a treatment for chronic musculoskeletal pain, but this was influenced by personal factors such as age, severity of pain, and travel/financial considerations. These findings highlight potential barriers that should be addressed to ensure the successful uptake of rTMS in a clinical setting.

Participants found rTMS to be sophisticated, yet confronting, due to the unfamiliarity of the medical equipment. One reason for perceptions of confrontation may be the fact that the use of rTMS has yet to be recognised as a mainstream treatment for chronic musculoskeletal pain. Indeed, previous literature has demonstrated that clinicians have limited understanding of rTMS and its application, likely influencing the inclusion of rTMS in the therapeutic plan for patients [24]. Alternatively, given that all participants associated rTMS with a dentist chair, previous dental experience may have led to subconscious levels of apprehension.

Interestingly, the sophisticated appearance of the technology also elicited greater expectations regarding treatment effectiveness. This is consistent with existing literature suggesting associations between increased apprehension or fear and expectations of treatment effect [25-27]. Such findings are perhaps unsurprising, as participants throughout the study indicated that, while confronting, the sophisticated nature of rTMS promoted greater expectations regarding pain relief.

Participants expressed their desire to seek health professional recommendations when deciding to consider rTMS as a treatment. In particular, participants highlighted physicians and patient testimonials as a valued source of endorsement. This finding highlights the need for clinicians to be trained and equipped with information regarding rTMS as they play an important role in facilitating awareness and fostering shared-decision making. Whilst participants in this study affirmed the need for health professional endorsement, there is no literature that examines the perceptions of clinicians in terms of the therapeutic use of rTMS for chronic musculoskeletal pain. This area represents an intriguing avenue for further research. 
Participants in this study also expressed that their willingness to utilise rTMS was either facilitated or prevented by personal circumstances. Age was one such characteristic, with older generations being perceived as less willing to engage in rTMS when compared to younger generations. This aligns with the Generational Cohort Theory, which suggests that certain time periods share similar life experiences that result in generational beliefs and characteristics [28]. This model supports the possibility that limited technological exposure, or exposure to times with less pervasive technology, among older generations may account for their sceptical perceptions towards rTMS when compared to younger, more familiar individuals [29]. Thus, future interventions should consider targeting promotional awareness of rTMS in older generations to ensure the successful utility of rTMS in a clinical setting.

Pain severity and location were also identified as key factors influencing an individual's motivation in accepting rTMS as a treatment option. Participants with more severe or debilitating pain were considered to be more likely to utilise rTMS, suggesting that willingness to seek rTMS could be fuelled by previously unsuccessful treatments. This is supported by literature that identifies desperation as a distinct characteristic for seeking alternative medicines [27]. Additionally, participants believed rTMS was only effective for conditions localised at the head and neck. While the reasons for this belief were not explained, it may be related to the common misconception that pain management strategies should be focused on the peripheral tissue (e.g., massage, manipulation) [30]. In contrast to these findings, results from previous studies show that participants with psychological conditions demonstrated good knowledge regarding rTMS [19, 31-33]. The longstanding utility of non-invasive brain stimulations in psychiatric settings may therefore contribute to greater familiarity and understanding of the intervention [34]. Indeed, participant education is an important component of maximising the clinical utility of this intervention. Future research should aim to investigate the development of educational and awareness tools as a means of increasing potential participants' knowledge and assessing their impact on their willingness to engage in rTMS.

Extended travel times or repeated sessions of the intervention were barriers to potential utilisation of rTMS. One plausible reason for this finding may be that the majority of participants were of working age, and were unable to accommodate multiple rTMS sessions between other commitments. Hence, participants expressed greater acceptance of one extended rTMS session when compared to repeated sessions. Cost was also highlighted as a barrier, with participants communicating the need for rTMS to be affordable and covered by health funding. Perhaps the increasing availability of treatments for chronic musculoskeletal pain has created the expectation that rTMS should be competitively priced and partially covered by insurance [3]. Supported funding to ensure equal accessibility across socioeconomic classes, and distribution of rTMS devices in areas with high chronic pain prevalence could therefore be an important consideration moving forward.

Despite a rigours approach, this study is not without limitations. Female participants represented a larger portion of the sample, introducing a potential gender bias. While the prevalence of chronic musculoskeletal conditions is greater in women, future studies should investigate alternative approaches to increase the recruitment of male participants. Furthermore, the sample in this study presented with high levels of pain intensity, which may have influenced the perceptions reported. Further clarification of patient perceptions of rTMS with varying degrees of chronic pain intensity is warranted. Finally, a participation bias may exist where only those who felt confident to share their perspectives and experiences of their condition participated.

\section{Conclusion}

This study is the first to investigate how people with chronic musculoskeletal pain perceive rTMS as a treatment option. Data indicated that participants with chronic musculoskeletal pain were accepting of rTMS treatment if they were from a younger generation, perceived their pain as severe, and if their diagnosis was located around the head or neck region. Most importantly, the treatment was perceived by many to be sophisticated and participants had higher expectations on the efficacy of the treatment. Findings also suggested that participants desired education and medical professional 
recommendations regarding rTMS to relieve their apprehension towards the intervention. Future research should investigate the effectiveness of educational and awareness strategies regarding the use of rTMS for pain management. This may help facilitate the utilisation of rTMS into clinical practice.

\section{Abbreviations}

rTMS (Repetitive Transcranial Magnetic Stimulation)

\section{Declarations}

Ethical approval and consent to participate: This study received ethical approval from the Western Sydney University Human Ethics Research Committee (H13647). Written informed consent has been obtained from all participants.

Consent for publication: Not applicable

Availability of data and materials: The dataset supporting the conclusions of this article is included within the article and its additional files.

Competing interests: The authors declare that they have no competing interests.

Funding: This study did not receive any funding.

\section{Author Contributions}

$\mathrm{CT}, \mathrm{RC}$ and SS were involved in the conception of the study. GS contributed to data collection. All authors were involved in writing and editing the manuscript. All authors discussed the results and approved of the manuscript prior to submission.

Acknowledgements: None

\section{References}

1. International Association of the Study of Pain: Chronic Pain has arrived in the ICD-11. 2019. https://bit.ly/2FFWutH.Accessed 20 Jan 2021.

2. Hadi MA, McHugh GA, Closs SJ: Impact of chronic pain on patients' quality of life: A comparative mixed-methods study. J Patient Exp 2019, 6(2):133-141.

3. Skelly AC, Chou R, Dettori JR, Turner JA, Friedly JL, Rundell SD, Fu R, Brodt ED, Wasson N, Kantner S: Noninvasive nonpharmacological treatment for chronic pain: A systematic review update. Available from: https://wwwncbinlmnihgov/books/NBK556229/ 2020.

4. Klein MM, Treister R, Raij T, Pascual-Leone A, Park L, Nurmikko T, Lenz F, Lefaucheur J-P, Lang M, Hallett M et al: Transcranial magnetic stimulation of the brain: guidelines for pain treatment research. Pain 2015, 156(9):1601-1614.

5. Tekin A, Özdil E, Güleken MD, İlişer R, Bakım B, Öncü J, Çevik M, Kuran B: Effıcacy of high frequency [10 Hz] repetitive transcranial magnetic stimulation of the primary motor cortex in patients with fibromyalgia syndrome: a randomized, double blind, sham-controlled trial. J Musculoskelet Pain 2014, 22(1):20-26.

6. O'Connor SR, Tully MA, Ryan B, Bleakley CM, Baxter GD, Bradley JM, McDonough SM: Walking Exercise for Chronic Musculoskeletal Pain: Systematic Review and Meta-Analysis. Arch Phys Med Rehabil 2015, 96(4):724-734.e723.

7. Dougherty D, Conway PH: The "3T's" road map to transform US health care: the "how" of high-quality care. JAMA 2008, 299(19):2319-2321.

8. Drolet BC, Lorenzi NM: Translational research: understanding the continuum from bench to bedside. Transl Res 2011, 157(1):1-5. 
9. Stillianesis G, Cavaleri R, Tang CY, Summers SJ: Exploring Patient Perceptions of Noninvasive Brain Stimulation: A Systematic Review. Neuromodulation: Technology at the Neural Interface 2021; DOI: 10.1111/ner.13461.

10. Tong A, Sainsbury P, Craig J: Consolidated criteria for reporting qualitative research (COREQ): a 32-item checklist for interviews and focus groups. Int J Qual Health Care 2007, 19(6):349-357.

11. Liamputtong P: Qualitative research methods, 4th edition; 2013.

12. Treede R-D, Rief W, Barke A, Aziz Q, Bennett MI, Benoliel R, Cohen M, Evers S, Finnerup NB, First MB: Chronic pain as a symptom or a disease: the IASP Classification of Chronic Pain for the International Classification of Diseases (ICD-11). Pain 2019, 160(1):19-27.

13. Sargeant J: Qualitative research part II: Participants, analysis, and quality assurance. Journal of Graduate Medical Education 2012, 4(1):1.

14. Ghaljaie F, Naderifar M, Goli H: Snowball sampling: A purposeful method of sampling in qualitative research. Strides in Development of Medical Education 2017, 14(3).

15. Oliveira D, Mendonça L, Sampaio R, Castro-Lopes JM, Azevedo LF: The role of anxiety and depression symptoms on the outcomes of chronic low back pain multidisciplinary treatment - A prospective multicentre cohort study. Acta Reumatológica Portuguesa 2019.

16. Ferreira-Valente MA, Pais-Ribeiro JL, Jensen MP: Validity of four pain intensity rating scales. Pain 2011, 152(10).

17. Cane J, O'Connor D, Michie S: Validation of the theoretical domains framework for use in behaviour change and implementation research. Implementation Sci 2012, 7(1):37.

18. Atkins L, Francis J, Islam R, O'Connor D, Patey A, Ivers N, Foy R, Duncan EM, Colquhoun H, Grimshaw JM et al: A guide to using the Theoretical Domains Framework of behaviour change to investigate implementation problems. Implement Sci 2017, 12(1):77.

19. Walter G, Martin J, Kirkby K, Pridmore S: Transcranial magnetic stimulation: experience, knowledge and attitudes of recipients. Aust N Z J Psychiatry 2001, 35(1):58-61.

20. Thomas DR: Feedback from research participants: are member checks useful in qualitative research? Qualitative Research in Psychology 2017, 14(1):23-41.

21. Braun V, Clarke V: Using thematic analysis in psychology. Qualitative Research in Psychology 2006, 3(2):77-101.

22. Denzin NK, Lincoln YS: Handbook of Qualitative Research: SAGE Publications; 1994.

23. Carpenter C, Suto M: Qualitative Research for Occupational and Physical Therapists: A Practical Guide. In: $2008 ; 2008$.

24. Yonel H, Abdelghani M: Knowledge and attitude towards TMS: a brief educational intervention. Progress in Neurology \& Psychiatry 2020, 24(1):17-20.

25. Afkham Ebrahimi A, Nasr Esfahani M, Saghafi N: Patients' expectations and satisfaction with their treating physician. Razi Journal of Medical Sciences 2004, 11(41):367-375.

26. McClintock AS, Anderson T, Petrarca A: Treatment expectations, alliance, session positivity, and outcome: An investigation of a three-path mediation model. Journal of Clinical Psychology 2015, 71(1):41-49.

27. Corp N, Jordan JL, Croft PR: Justifications for using complementary and alternative medicine reported by persons with musculoskeletal conditions: A narrative literature synthesis. PloS one 2018, 13(7):e0200879.

28. Okros A: Generational Theory and Cohort Analysis. In: Harnessing the Potential of Digital Post-Millennials in the Future Workplace. edn. Edited by Okros A. Cham: Springer International Publishing; 2020: 33-51.

29. Alkire L, O'Connor GE, Myrden S, Köcher S: Patient experience in the digital age: An investigation into the effect of generational cohorts. Journal of Retailing and Consumer Services 2020, 57:102221.

30. Bishop MD, Bialosky JE, Cleland JA: Patient expectations of benefit from common interventions for low back pain and effects on outcome: secondary analysis of a clinical trial of manual therapy interventions. J Man Manip Ther 2011, 19(1):20-25. 
31. Mayer G, Faivel N, Aviram S, Walter G, Bloch Y: Repetitive transcranial magnetic stimulation in depressed adolescents: experience, knowledge, and attitudes of recipients and their parents. The Journal of ECT 2012, 28(2):104-107.

32. Lonergan B, Nguyen E, Lembo C, Hinchman C, Morales OG, Press DZ, Pascual-Leone A, Stern AP: Patient- and Technician-Oriented Attitudes Toward Transcranial Magnetic Stimulation Devices. J Neuropsychiatry Clin Neurosci 2018:appi.neuropsych.

33. Singh SM, Sharma M, Aggarwal A, Avasthi A: The knowledge, experience and attitudes of recipients of repetitive transcranial magnetic stimulation: A study from North India. Asian J Psychiatr 2018, 31:102-106.

34. Boes AD, Kelly MS, Trapp NT, Stern AP, Press DZ, Pascual-Leone A: Noninvasive brain stimulation: challenges and opportunities for a new clinical specialty. J Neuropsychiatry Clin Neurosci 2018, 30(3):173-179.

\section{Supplementary Files}

This is a list of supplementary files associated with this preprint. Click to download.

- Additionalfile1 Interviewguide.docx

- Additionalfile2.docx 